\title{
Au-Ni nanoparticles: Phase diagram prediction, synthesis, characterization, and thermal stability
}

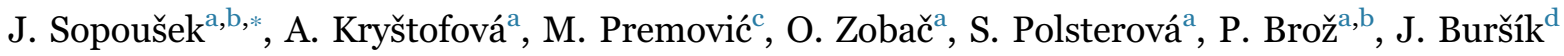 \\ a Masaryk University, Faculty of Science, Department of Chemistry, Kotlářská 2, 61137 Brno, Czech Republic \\ b Masaryk University, Central European Institute of Technology, CEITEC, Kamenice 753/5, 625 oo Brno, Czech Republic \\ ${ }^{\mathrm{c}}$ University of Pristina, Faculty of Technical Science, Kos. Mitrovica, Kneza Milosa 7, 4000 Kos. Mitrovica, Serbia \\ d Institute of Physics of Materials, Academy of Sciences of the Czech Republic, Žižkova 22, 61662 Brno, Czech Republic
}

\section{A R T I C L E I N F O}

\section{Keywords:}

Nanoalloy

CAPHAD

Phase diagram

Spinodal decomposition

\begin{abstract}
A B S T R A C T
The Au-Ni nanoparticles (NPs) were prepared by oleylamine solvothermal synthesis from metal precursors. The $\mathrm{Au}-\mathrm{Ni}$ phase diagram prediction respecting the particle size was calculated by the CALPHAD method. The hydrodynamic size of the AuNi NPs in a nonpolar organic solvent was measured by the dynamic light scattering (DLS) method. The average hydrodynamic sizes of the nanoparticle samples were between 18 and $25 \mathrm{~nm}$. The metallic composition of the AuNi NP samples was obtained by inductively-coupled plasma atomic emission spectroscopy (ICP-OES). The metallic fraction inside AuNi NPs was varied Au-(30-70) wt\%Ni. The steric alkylamine stabilization was observed. The individual AuNi NPs were investigated by transmission electron microscopy (TEM). The dry nanopowder was also studied. The structures of the aggregated samples were investigated by scanning electron microscopy (SEM). The AuNi NPs reveal randomly mixed face-centered cubic (FCC) crystal lattices. The phase transformations were studied under inert gas and air. The samples were studied by differential scanning calorimetry (DSC).
\end{abstract}

\section{Introduction}

The behavior of the macro-sized alloy (bulk alloy) differs from a system of individual nano alloy particles (nanoalloy) despite that both bulk and nanoalloy have the same composition. The fundamental reasons are a high ratio between numbers of surface and volume atoms and the presence of the adsorbed or bonded molecules (ligands) on the nanoparticle surface. The main function of the ligands is to stabilize nanoparticles. The second function is to functionalize the nanoparticle surface for subsequent applications.

The AuNi nanoparticles could provide opportunities to combine properties of gold nanoparticles, which are considered as non-toxic and are intensively investigated now, in conjunction with magnetic properties of nickel atoms. These nanoparticles could be promising carriers for surface anchored agents in diagnostics, medicine, drug delivery, etc.

The phase behavior of the AuNi alloy in the macroscopic form (bulk) is well known. The stable phase diagram was clarified experimentally during the 20th century. The AuNi bulk alloy represents a non-ideal system with limited mutual miscibility of the metals in the solid state at low-temperature region [1].

At the beginning of this century (2005), Wang and colleagues performed a detailed thermodynamic assessment of the phases of the
AuNi system using the CALPHAD method [1]. The result of their work was the accurate phase diagram of the $\mathrm{Au}-\mathrm{Ni}$ system, which reveals the critical point at $816^{\circ} \mathrm{C}(\mathrm{Au}-74 \mathrm{at} \% \mathrm{Ni})$ and the congruent point at $941{ }^{\circ} \mathrm{C}(\mathrm{Au}-36$ at\% Ni). The accepted description of the phases of the AuNi system [1] is in accordance with the thermodynamic data, such as entropy and enthalpy of mixing, the activity of both gold and nickel in the AuNi bulk.

Despite the FCC lattice of pure $\mathrm{Au}$ and $\mathrm{Ni}$, their alloy reveals decomposition to the Au-rich FCC phase (FCC_Au) and the Ni-rich FCC phase (FCC_Ni) at temperatures below the critical point. The thermodynamic equilibrium of the two phases (FCC_Au + FCC_Ni) is created by either discontinuous precipitation or by the spinodal decomposition of the supersaturated FCC AuNi alloy [2]. The spinodal decomposition occurs at a low-temperature range up to $250^{\circ} \mathrm{C}$. The discontinuous precipitation (nucleation and growth) takes place at high-temperature range $(250-816){ }^{\circ} \mathrm{C}$. The kinetics of both phase transformations is slow [2]. The earlier time of the start of the discontinuous precipitation is $250 \mathrm{~s}$ at $600{ }^{\circ} \mathrm{C}$. The earlier time of the start of the spinodal decomposition is $1000 \mathrm{~s}$ at $150{ }^{\circ} \mathrm{C}$. It appears that both kinds of the phase transformations are diffusion controlled. Rates of chemical diffusion of gold and nickel in the fcc AuNi bulk alloy can be obtained from diffusional mobilities of both gold and nickel [3].

\footnotetext{
* Corresponding author at: Masaryk University, Faculty of Science, Department of Chemistry, Kotlářská 2, 61137 Brno, Czech Republic.

E-mail address: sopousek@mail.muni.cz (J. Sopoušek).
} 
Irradiation-induced spinodal decomposition has been also observed insitu on thin AuNi foil in an electron microscope with $0.4-1 \mathrm{MeV}$ electron irradiation up to approx. $600{ }^{\circ} \mathrm{C}$ [4].

The properties of AuNi nanoparticles should be inferred from the properties of the bulk alloys but deviations caused by nanoscale particle size and by the presence of ligands on the surface were observed. The preparations of the AuNi nanoparticles was realized using physical methods and by routes of chemical synthesis. The products of these methods are different types of nanoparticles as core@shell, supersaturated AuNi NPs, and Janus NPs. The last type is a special type of nanoparticle, its surface has two or more distinct physical properties.

A simple physical technique for preparing of AuNi particles is a dewetting method $[5,6]$. The first step of the procedure is physical vapor deposition (PVD) of thin $\mathrm{Au} / \mathrm{Ni}$ bilayer on a suitable substrate. The heating of the sample at temperatures in two phase region causes separation of the metal bilayer from the substrate surface and the formation of Janus Au/Ni bimetallic particles. Herz et al. [6] prepared by this way submicron particles that were formed by (FCC_Au + FCC_Ni) phases. It is possible to homogenize the particles if they are annealed at a high temperature in the FCC AuNi single phase region. Consequently, the formation of the FCC magnetic supersaturated AuNi particles is possible after cooling to ambient temperature [7]. The main disadvantage of the dewetting method is that particles below approx. $0.1 \mu \mathrm{m}$ cannot be prepared.

Core@shell nanoparticles that consist of Au cores covered by $\mathrm{Ni}$ $(\mathrm{Au} @ \mathrm{Ni})$ can be prepared by the metal gas condensation method [8]. The product has a huge magnetization generated by Faraday Induction. The magnetism is not lost even if the oxidation of the $\mathrm{Au} @ \mathrm{Ni}$ nanoparticles to particles containing $\mathrm{NiO}$ occurred.

The wet chemical synthesis of AuNi NPs is more promising than physical methods. The synthesis can use inorganic $\mathrm{Ni}^{2+}$ salts and tetrachloroauric acid. Sodium tetrahydroborate $\left(\mathrm{NaBH}_{4}\right)$ is often used as a reducing agent. Different electrochemical potentials of the gold and the less noble nickel adversely affect the reduction step. Therefore, it is easier to synthesize the core@shell nanoparticles (Au@Ni NPs) than to prepare nanoparticles with a homogeneous supersaturated composition (AuNi NPs). The Au@Ni NPs were prepared by Chiu et al. in 2009 [9] using a water-in-oil microemulsion. Also, other authors obtained similar products $[10,11]$. Alternatively, laser ablation of $\mathrm{Ni}$ target in Au colloidal solution can also be used for NP synthesis [12]. At these conditions, the formation of bimetallic Au@Ni NPs and complex NiO:Au nanoparticles occurred. The preparation of the Ni@Au nanoparticles ( $\mathrm{Ni}$ in the center, shell enriched in $\mathrm{Au}$ !) that are stable at room temperature is also very interesting research that was done by Authen and a team in 2008 [13]. They obtained the magnetic Ni-Au nanoparticles of a small size $(3 \mathrm{~nm})$ using PAMAM (polyamidoamine) dendrimer and inorganic salts of $\mathrm{Au}$ and $\mathrm{Ni}$.

The nanoparticles based on AuNi alloys are considered promising catalysts for chemical reactions [14]. For example aerobic oxidative esterification of aldehydes with alcohols [15], hydrogen generation by hydrolysis of basic $\mathrm{NaBH}_{4}$ solutions [16], electrocatalyzed borohydride oxidation [11]. Fine nanoparticles of $\mathrm{Ni}$ on pNIPAM-coated $\mathrm{Au}$ nanoparticles can be used for the preparation of special sensors [17].

Generally, the nanoparticles consisting of gold and nickel are objects, which are discussed in theoretical and experimental nanoparticle research. The phenomenon of the phase separation of the supersaturated $\mathrm{Au}-\mathrm{Ni}$ nanoparticle was theoretically investigated by the groups of Herz, Friák, and others [18] but the experimental preparation of the supersaturated AuNi nanoparticles represents a great challenge to the synthetic research.

\section{Prediction of Au-Ni nanoalloy phase diagram}

Phase diagram prediction of AuNi nanoalloys was performed using a similar method as presented by Lee and Park [19,20] and others $[21,22]$. The employed CALPHAD method [20] is based on the minimization of the molar Gibbs energy of the phases present in the entire system. The Gibbs energy of the phase (liquid or FCC solid) that involve $1 \mathrm{~mol}$ of the individual nanoparticles is given by Eq. (1).

$G^{\text {Total }}=G^{\text {Bulk }}+G^{\text {Surface }}$

where $G^{\text {Bulk }}$ is the Gibbs energies of the bulk binary phase expressed as Eq. (2).

$G^{\text {Bulk }}=x_{A} G_{A}^{o}+x_{B} G_{B}^{o}+R T\left(x_{A} \ln x_{A}+x_{B} \ln x_{B}\right)+G^{E x, B u l k}$

$x_{A}$ and $x_{B}$ are mole fractions of $\mathrm{A}$ and $\mathrm{B}, G_{A}^{o}$ and $G_{B}^{o}$ are the standard Gibbs energies of $\mathrm{A}$ and $\mathrm{B}, R$ is the universal gas constant, $T$ is the temperature and $G^{E x, B u l k}$ is the excess Gibbs energy of the bulk which is given by Eq. (3).

$G^{E x, B u l k}=x_{A} x_{B} \sum_{v} L^{v}(T)\left(x_{B}-x_{A}\right)^{v}$

where index $v=0,1,2, \ldots$ in temperature dependent parameters

$L^{v}(T)=a_{v}+b_{v} \cdot T+c_{v} \cdot T \cdot \ln (T)$

The second term in Eq. (1) is the Gibbs energy of the surface of the nanoparticles $G^{\text {Surface }}$. This surface energy for isotropic spherical particles is expressed by

$G^{\text {Surface }}=\frac{2 C \sigma V}{r}$

where $C$ is a correction factor considering the effects from the shape the surface strain due to nonuniformity, and the uncertainty of the surface tension measurements, estimated for a liquid to be 1.00 and for an fcc solid structure 1.05 [23], $\sigma$ is the surface tension, $r$ is the radius of the particle and $V$ is the molar volume.

The molar volume for the binary system is expressed as the sum of fractions of each constituent (Eq. (5)).

$V=x_{A} V_{A}+x_{B} V_{B}$

For calculation of the surface tension of a binary liquid alloy the Butler equation [24] can be used expressed by

$$
\begin{aligned}
\sigma & =\sigma_{A}+\frac{1}{A_{A}}\left(G_{A}^{\text {Surface }}-G_{A}^{E x, B u l k}\right)+\frac{R T}{A_{A}} \ln \left(\frac{1-x_{B}^{S}}{1-x_{B}}\right) \\
& =\sigma_{B}+\frac{1}{A_{B}}\left(G_{B}^{\text {Surface }}-G_{B}^{E x, B u l k}\right)+\frac{R T}{A_{B}} \ln \left(\frac{x_{B}^{S}}{x_{B}}\right)
\end{aligned}
$$

where $\sigma_{A}$ and $\sigma_{B}$ are the surface tensions of pure species A and B, $A_{A}$ and $A_{B}$ are the superficial areas occupied by the liquid component $\mathrm{A}$ and B, $G_{A}^{\text {Surface }}$ and $G_{B}^{\text {Surface }}$ are the partial Gibbs energies of component A and B in the surface and $G_{A}^{E x, B u l k}, G_{B}^{E x, B u l k}$ are the partial Gibbs energies of component $\mathrm{A}$ and $\mathrm{B}$ in bulk.

The partial Gibbs energy $G_{A}^{\text {Surface }}$ of component A is presented as Eq. (7).

$G_{A}^{\text {Surface }}=\beta^{\text {mix }} G^{\text {Ex,Bulk }}$

where $\beta^{m i x}$ is a parameter corresponding to the ratio of the coordination number in the surface in the bulk and equal to $\beta^{\text {Pure }}$ and the parameter is estimated to be 0.83 [25] and later on 0.85 [20].

The parameter $\beta^{\text {Pure }}$ is determined from Eq. (8).

$\sigma_{A} A_{A}=\left(1-\beta^{\text {Pure }}\right) \Delta H_{L G, A}$

where $\Delta H_{L G, A}$ is the heat for the liquid-gas transformation of metal A. A similar equation for solid $\beta^{\text {Pure }}$ is given by Eq. (9).

$\sigma_{A} A_{A}=\left(1-\beta^{\text {Pure }}\right) \Delta H_{S G, A}$

where $\Delta H_{S G, A}$ is the heat for solid-gas transformation of metal A.

The parameter $\beta^{\text {Pure }}$ for solid state was estimated to be 0.84 [20], which is close to liquid metals. Accordingly, it is considered that the surface relaxation and rearrangement effects are almost the same for both liquid and solid metals. Therefore, if the differences in shape and surface strain with respect to composition are ignorable. According to 
Table 1

Physical properties of $\mathrm{Au}$ and $\mathrm{Ni}$ pure elements ( $\mathrm{L}$ - liquid, S - solid (i.e. fcc) phase).

\begin{tabular}{lll}
\hline Variables & Equations & Reference \\
\hline Surface tension & $\sigma_{A u}^{L}(N / m)=1.33-1.4 \cdot 10^{-4} T$ & {$[27]$} \\
& $\sigma_{A u}^{S}(N / m)=1.947-4.3 \cdot 10^{-4} T$ & {$[28]$} \\
& $\sigma_{N i}^{L}(N / m)=2.488-3.93 \cdot 10^{-4} T$ & {$[22]$} \\
& $\sigma_{N i}^{S}(N / m)=2.94-3.92 \cdot 10^{-4} T$ & {$[22]$} \\
Molar volume & $V_{A u}^{L}\left(m^{3} / m o l\right)=1.02582 \cdot 10^{-5}+7.797 \cdot 10^{-10} T$ & {$[27]$} \\
& $V_{A u}^{S}\left(m^{3} / m o l\right)=1.07109 \cdot 10^{-5}$ & {$[29]$} \\
& $V_{N i}^{L}\left(m^{3} / m o l\right)=5.85 \cdot 10^{-6}+9.02 \cdot 10^{-10} T$ & {$[30]$} \\
& $V_{N i}^{S}\left(m^{3} / m o l\right)=6.60 \cdot 10^{-6}$ & {$[31]$} \\
\hline
\end{tabular}

this conclusion, the surface tension of solid alloys can be predicted also by the Butler equation [24].

The Butler Eq. (6) [24] is implemented in the software package stxs-xbt.exe [26]. This software was used for the calculation of surface tensions of liquid and solidus alloy phases. Necessary data for the calculation are summarized in Table $1 .$.

Data for surface tension of pure nickel are average values of surface tension from literature $[30,32-37]$ that are summarized in reference [22].

Concentration dependences of surface tension for liquid and solid phases at $1800 \mathrm{~K}$ are presented in Fig. 1.

Calculated concentration dependence of the surface tensions of liquid and solid phase multiplied by the (linear) concentration dependence of molar volume makes it possible to express the concentration dependence of the excess surface Gibbs energy for nanoalloys (using Eqs. 4 and 5) in liquid and in the solid phase. The excess surface Gibbs energy of nanoparticles has a Redlich-Kister dependency on composition,

$G^{E x, \text { Nano }}=x_{A} x_{B} \sum_{v} L_{v}^{\text {Nano }}(T)\left(x_{B}-x_{A}\right)^{v}$ where $v=0,1,2, \ldots$

where $L_{v}^{\text {Nano }}$ is expressed as

$L_{v}^{\text {Nano }}=L_{v}^{\text {Bulk }}+L_{v}^{\text {Surface }}=\left(a+\frac{a^{\prime}}{r}\right)+\left(b+\frac{b^{\prime}}{r}\right) T+\left(c+\frac{c^{\prime}}{r}\right) T \ln (T)+\ldots$

where the parameters $a, b$, and $c$ are the same as those for the bulk phase and $a^{\prime}, b^{\prime}, c^{\prime}$ are empirical constants (calculated correction for nanoparticles).

The calculations of the surface Gibbs energies of pure components were also done, using Eq. (4). The calculated values for pure compo-

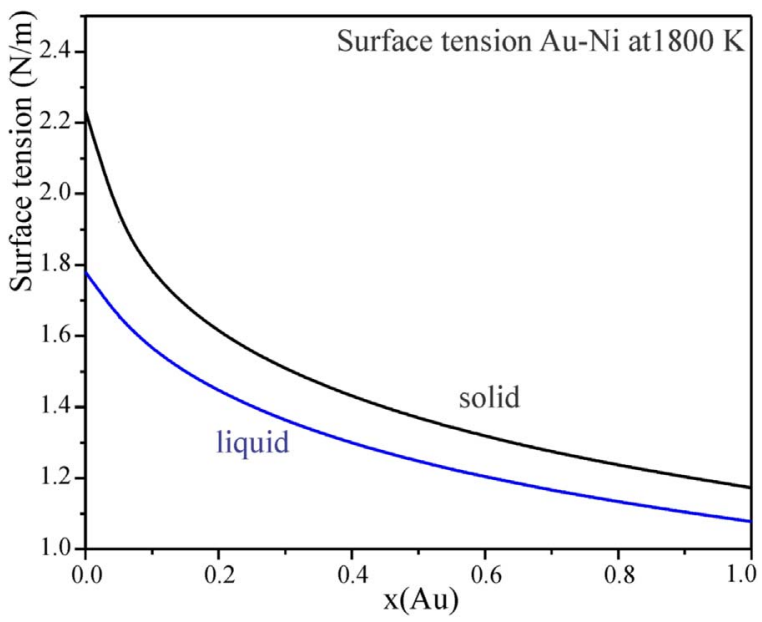

Fig. 1. Calculated surface tensions of liquid and solid phases in the $\mathrm{Au}-\mathrm{Ni}$ system at $1800 \mathrm{~K}$.

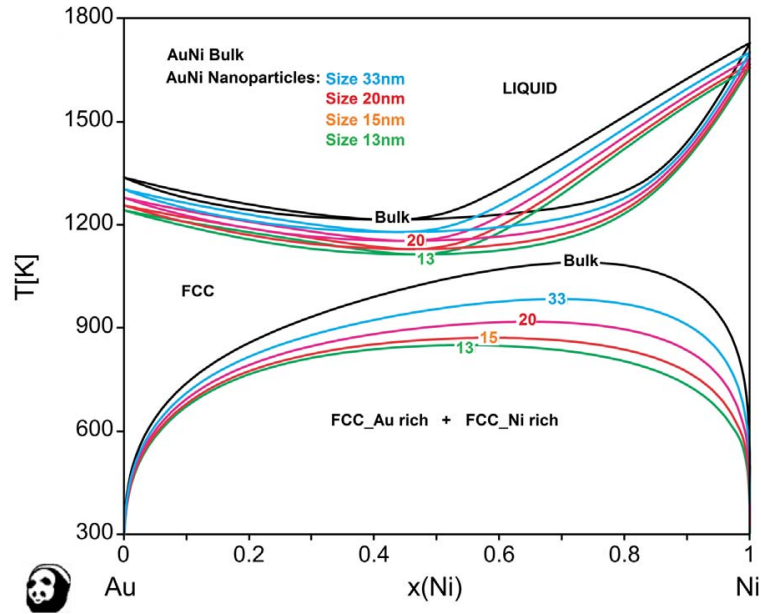

Fig. 2. Predicted Au-Ni phase diagram of bulk (black solid line)and nanoparticles of different core size (colored lines).

nents are the same as obtained by Park and Lee [20] for gold and by Sopousek et al. [22] for a nickel. - Calculated corrections (surface Gibbs energy of alloys and pure components) are a function of $(1 / \mathrm{r})$, for which we introduce the function "reciprocal radius" (RR).

The thermodynamic parameters for the $\mathrm{Au}-\mathrm{Ni}$ nanoalloy were assessed on the basis of the above-given description. The thermodynamic parameters for $\mathrm{Au}-\mathrm{Ni}$ nanoalloy are given in supporting file, where the data for the bulk system are taken from Wang et al. [1]. Presented parameters in supporting file can be used as an input data in different software (such as Thermo-Calc, Pandat, MTData, FactSage and many others). By, changing a size, the phase diagrams of the particles with diameters $5-100 \mathrm{~nm}$ can be calculated. Nanosystems were defined with three liquid parameters and two solid parameters (same as in bulk system). As an illustration, a phase diagram of the bulk Au-Ni system and the nanoalloys of 13, 15, 20 and $33 \mathrm{~nm}$ size are shown in Fig. 2.

Fig. 2 shows that the nano-alloy size influences the position of the phase field boundaries. The decreasing of the nanoparticle size shifts the temperatures of the phase transformations to low temperatures. The composition of the coexisting phases changes also.

The Gibbs energy of the nanoparticle is influenced by several contributions. The alloy surface energy and chemical composition were the subjects of the presented work. The stabilization shell that consists from organic ligands was excluded from our calculations. The size of the AuNi NPs was approximated by the size of the AuNi alloy core. There exist also other contributions that can influence the energy and the stability of the nanoparticle system and they were investigated by other authors: shape factor [38], bimodal phase separation [39], stress effects [40], structure stabilities [41,42].

The final note should be given concerning heat content of both the bulk and nanoalloy. The heat content (enthalpy) of $1 \mathrm{~mol}$ of the spinodally decomposed sample (ie. a sample that consists of the FCC_Au and FCC_Ni phases) changes smoothly when the sample is heated up under equilibrium conditions. The negative value of the first derivative of the enthalpy is the heat capacity of the sample. The heat content of the sample above the (FCC_Au + FCC_Ni)/(FCC solid solution) phase boundary does not reveal any stepwise change because the same thermodynamic model is used for all phases (FCC_Au, FCC_Ni, FCC solid solution). It implies that the (FCC_Au + FCC_Ni)/(FCC solid solution) phase boundary cannot be identified by calorimetry measurements (for example by differential scanning calorimetry (DSC)). 


\section{Experimental section}

\subsection{Materials}

The following chemicals were all used as obtained: pure gold metal ( $5 \mathrm{~N}$ purity), aqua regia mixed from hydrochloric acid $(\mathrm{HCl}, 35 \%$, chemical grade: purists p. a., Penta) and nitric acid $\left(\mathrm{HNO}_{3}, 69 \%\right.$, purum, Penta) in a 3:1 vol ratio, water (deionized, $<1 \mu \mathrm{S} / \mathrm{cm}$ ), liquid nitrogen ( $>5 \mathrm{~N}$, Messer), oleylamine (ACROS Organics, $\mathrm{C}_{18} \mathrm{H}_{35} \mathrm{NH}_{2}$, redestilled from tech. $80-90 \%$ grade, stored above calcium hydride $\mathrm{CaH}_{2}$ under nitrogen), tetraoctylammonium chloride $\left(\mathrm{N}\left(\mathrm{C}_{8} \mathrm{H}_{17}\right)_{4} \mathrm{Cl}\right.$, viscose liquid, 90\%), nickel(II) acetylacetonate ( $\mathrm{Ni}(\mathrm{AcAc})_{2}, 95 \%$, Aldrich), octadecene $\left(\mathrm{C}_{18} \mathrm{H}_{36}\right.$, redistilled from $98 \%$ grade, stored above sodium metal under nitrogen, Aldrich), hexane (purum, Lachner). Chromafil 0.45 $\mu \mathrm{m}$ PES filter (Machery-Nagel) was used.

\subsection{Preparation of metal precursors}

The synthesis of the gold precursor was started from gold metal, which was dissolved in aqua regia to tetrachloro auric acid $\left(\mathrm{HAuCl}_{4}\right)$ at $70{ }^{\circ} \mathrm{C}$. The volume of the $\mathrm{HAuCl}_{4}$ solution was reduced to approx. $90 \%$ at a temperature close to $105{ }^{\circ} \mathrm{C}$. The crystallization of $\mathrm{HAuCl}_{4}$ was finished by slow evaporating of the solution at $40^{\circ} \mathrm{C}$. The yellow crystals of $\mathrm{HAuCl}_{4}$ were prepared. $\mathrm{HAuCl}_{4}$ was dissolved in water (12 $\mathrm{mg} \mathrm{Au} / \mathrm{ml}$ ), filtered with $0.45 \mu \mathrm{m}$ PES filter, and saved for next use.

The adapted procedure derived from instructions given by Leff [43] was used for the $\mathrm{HAuCl}_{4}$ substance transfer from water to oleylamine phase. The tetraoctylammonium chloride $\mathrm{N}\left(\mathrm{C}_{8} \mathrm{H}_{17}\right){ }_{4} \mathrm{Cl}$ was used as a phase converter in the following procedure. The aqueous solution (5 ml) of $\mathrm{HAuCl}_{4}\left(60 \mathrm{mg}\right.$, i.e. $\mathrm{n}_{\mathrm{Au}}=0.305 \mathrm{mmol}$ of gold metal $)$ was mixed with the toluene solution (5 ml) involving approx. $2.5 \mathrm{n}_{\mathrm{Au}} \mathrm{mmol}$ (383 mg) of $\mathrm{N}\left(\mathrm{C}_{8} \mathrm{H}_{17}\right)_{4} \mathrm{Cl}$. Thus two-phase extraction system was created. Under gentle stirring at rotary extractor $(20 \mathrm{~min})$, the gold in the form of $\mathrm{HAuCl}_{4}$ (in aqueous solution) was transferred to the $\left[\mathrm{N}\left(\mathrm{C}_{8} \mathrm{H}_{17}\right)_{4}\right]^{+}\left[\mathrm{AuCl}_{4}\right]^{-}$complex (in toluene solution). The transfer was indicated by yellow color moving from water to toluene phase. The extraction efficiency near $95 \%$ was evaluated by the gravimetric method (i. e. toluene was evaporated and the solid residue was heated up to the formation of anhydrous $\mathrm{HAuCl}_{4}$ at $350{ }^{\circ} \mathrm{C}$ or the formation of gold metal at $800^{\circ} \mathrm{C}$ ). Once the extraction was finished, the aqueous phase was separated and discarded. The extraction procedure was done always before the nanoparticle synthesis because of low stability of the gold precursor in the organic phase.

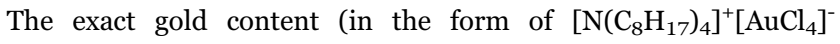
complex) in toluene solution was evaluated after extraction by an oscillating densitometer (DMA $5000 \mathrm{M}$, Anton Paar, accuracy \pm $0.000001 \mathrm{~g} / \mathrm{ml}$ ). It was found that the density of toluene solution with the gold complex is a linear function of the gold metal content.

The subsequent step was transferring gold from toluene into oleylamine. The toluene solution of the gold complex was slowly titrated by the $5 \mathrm{vol} \%$ oleylamine in toluene. During this procedure, the yellow color has changed to brown. The titration was stopped when the color did not change anymore. Finally, $8 \mathrm{ml}$ of oleylamine was added and the mixture was concentrated under vacuum to volume close to $8 \mathrm{ml}$. The solution of the gold precursor in oleylamine was a clear liquid with a yellow/brown color.

The nickel(II) acetylacetonate $\mathrm{Ni}(\mathrm{AcAc})_{2}$ was used as a nickel precursor. Dissolving of solid $\mathrm{Ni}(\mathrm{AcAc})_{2}$ in oleylamine needed heating to approx. $40{ }^{\circ} \mathrm{C}$.

\subsection{Nanoparticle synthesis}

The samples of the AuNi nanoparticles were synthesized by solvothermal co-reduction of gold and nickel precursors. The synthesis was similar to the preparation given in our previous report [44]. The tetrachloro auric acid $\left(\mathrm{HAuCl}_{4}\right)$ and nickel(II) acetylacetonate
$\left(\mathrm{Ni}(\mathrm{AcAc})_{2}\right)$ in oleylamine $(\mathrm{OAm})$ were used as gold and nickel precursors, respectively. The main step of the synthesis is an injection of the metal precursors into the solvent mixture of oleylamine and octadecene.

The synthesis of nanoparticles was performed in a three-necked flask $(250 \mathrm{ml})$, which was filled with a mixture of octadecene $(30 \mathrm{ml})$ and oleylamine $(22 \mathrm{ml})$. This arrangement enabled to heat the solvent mixture in the flask on a $\mathrm{SnPb}$ metal bath, to work under a nitrogen atmosphere at the elevated temperature, and stirring. The solvent mixture in the flask was degassed under vacuum at $140{ }^{\circ} \mathrm{C}$. Nitrogen was then blown through the flask and the solvent mixture was heated up to $230^{\circ} \mathrm{C}$.

The preparation of the nanoparticles with an Au50at\%Ni stoichiometry composition was performed as follows. The solution containing $\mathrm{Ni}(\mathrm{AcAc})_{2}$ (39 mg, $0.152 \mathrm{mmol}$ ) in $4 \mathrm{ml}$ of oleylamine was prepared and mixed with the solution that was obtained during extraction procedure and contained $30 \mathrm{mg}(0.152 \mathrm{mmol})$ of gold in the form of the gold complex in $4 \mathrm{ml}$ of oleylamine. A transparent green solution was created by mixing the precursor solutions. The particular masses of the precursors were used for preparing nanoparticles outside Au50at\% Ni stoichiometry.

The precursor mixture was injected into the solvent mixture that was preheated to $230^{\circ} \mathrm{C}$. Coloration of the reaction mixture to dark brown was observed after injection. The constant temperature $230{ }^{\circ} \mathrm{C}$ was held within $10 \mathrm{~min}$, after that the flask with the reaction mixture was removed from the metal bath and cooled by ambient air. A colloidal brown/pink solution of AuNi nanoparticles in the solvent mixture was obtained.

The synthesized bimetallic AuNi nanoparticles were separated in a high-speed centrifuge. The product was purified by repeated dissolving in hexane and by subsequent centrifuging. The AuNi nanoparticles were protected from oxidation by storing under a layer of hexane.

\subsection{Instrumentations}

\subsubsection{Dynamic light scattering (DLS)}

The hexane colloidal solutions of the nanoparticles (at $25^{\circ} \mathrm{C}$ ) were characterized by the DLS method on a Zetasizer Nano ZS ZEN 3500 instrument (Malvern UK) working at the scattering angle of $173^{\circ}$. The method measures a hydrodynamic size of NPs, which is given by both the metal core and the stabilizing organic layer of the core.

\subsubsection{Overall chemical analysis}

The chemical composition of the AuNi NP samples was obtained by elemental analysis. The AuNi colloid was gently dried under vacuum at a laboratory temperature. The powder was weighed and dissolved in nitric acid at elevated temperature. The $\mathrm{Au}$ and Ni metal content was analyzed by inductively-coupled plasma atomic emission spectroscopy (ICP-OES) calibrated on $\mathrm{Au}$ and $\mathrm{Ni}$ pure metals. The difference between the mass of the dry sample and the weight of the metal content was presumed to be the mass of organic matter.

\subsubsection{Infrared spectroscopy (IR)}

FTIR spectra were measured on a Bruker Tensor 27 spectrometer (the spectral range $4000-400 \mathrm{~cm}^{-1}$, resolution $4 \mathrm{~cm}^{-1}$ ) equipped with a Diamond-ATR accessory device. The IR spectra were evaluated with the OPUS 7.2 software.

\subsubsection{UV-vis spectroscopy}

The spectra of the AuNi colloids in the range (200-900) nm were obtained using a UNICAM UV/Vis Spectrometer UV4 and quartz cuvettes.

\subsubsection{Transmission electron microscopy (TEM and HRTEM)}

The metal cores of the AuNi NPs were investigated by electron microscopy because this technique is sensitive to heavier elements and 
Table 2

The size and composition (ICP-OES) of AuNi NPs after synthesis.

\begin{tabular}{llllll}
\hline Sample & $\begin{array}{l}\text { Size DLS/ } \\
\text { TEM [nm] }\end{array}$ & $\begin{array}{l}\text { Au [wt } \\
\%]\end{array}$ & $\begin{array}{l}\text { Ni [wt } \\
\%]\end{array}$ & $\begin{array}{l}\text { Organic matter } \\
\text { [wt\%] }\end{array}$ & Metal composition \\
\hline AuNi 1 & $33.2 / 13$ & 18 & 9 & 73 & Au-63 at\%Ni \\
AuNi 2 & $20.4 / 15$ & 64 & 11 & 26 & Au-36 at\%Ni \\
AuNi 3 & $35.5 /-$ & 20 & 8 & 72 & Au-55 at\%Ni \\
AuNi 4 & $26.6 /-$ & $\mathrm{x}$ & $\mathrm{x}$ & $\mathrm{x}$ & Au-55 at\%Ni \\
\hline
\end{tabular}

${ }^{\mathrm{a}}$ Conscientiously purified sample.

less sensitive to light elements that form an organic stabilizing layer of the NPs. To prepare samples, a drop of a diluted AuNi colloidal suspension was placed on a holey carbon film coated $\mathrm{Cu}$ grid and allowed to dry by evaporation at ambient temperature. The size and shape of AuNi NP cores were investigated using a Philips CM12 STEM microscope with a thermoemission source operated at $120 \mathrm{kV}$ and a JEOL JEM $2100 \mathrm{~F}$ high-resolution TEM (HRTEM) with an FEG source operated at $200 \mathrm{kV}$ (point resolution of $2.3 \AA$ ). Both transmission electron microscopes were equipped with energy dispersive X-ray (EDX) detectors.

\subsubsection{Powder $X$-ray diffraction (XRD)}

Measurements were carried out on a GNR Europe XRD 600 diffractometer equipped with a Co lamp, $\lambda \mathrm{Ka}=1.7903 \AA, 40 \mathrm{kV}$, $15 \mathrm{~mA}$, with theta/2theta configuration. Samples were measured in step scan of $0.2 \mathrm{deg}$ for $10 \mathrm{~s}$ in reflection mode on plastic or aluminium sample holders. A 1D detector DECTRIS Mythen2R was used. The samples were treated under air at ambient temperature.

\subsubsection{High-temperature X-ray powder diffraction (HTXRD)}

$X^{\prime}$ Pert PRO PANalytical (Netherlands) diffractometer with CoKa radiation was used for HTXRD. An HTK-16N Anton Paar heating chamber was applied in step mode that enables sample heating on the platinum strip. The XRD diffractograms were collected under vacuum $\left(10^{-4} \mathrm{mbar}\right)$ and in the air holding at each temperature during collecting data. The average heating rate included sample heating and hold at temperature during measurement were $5 \mathrm{~K} / \mathrm{min}$. The HTXRD pattern computation enabled evaluation of phase composition, lattice constants of phases, and crystallinity by Rietveld method.

\subsubsection{Differential scanning calorimetry (DSC)}

The thermal properties of AuNi NPs were examined on a Netzsch STA $409 \mathrm{CD} / 3 / 403 / 5 / \mathrm{G}$ apparatus under flowing $\left(70 \mathrm{~cm}^{3} \mathrm{~min}^{-1}\right)$ pure $(6 \mathrm{~N})$ argon with the heating rate of $10 \mathrm{~K} / \mathrm{min}$ from room temperature to approx. $1100{ }^{\circ} \mathrm{C}$. The samples (approx. $10 \mathrm{mg}$ ) were measured in $\mathrm{Y}_{2} \mathrm{O}_{3}$-coated alumina crucibles covered with a lid. The oxygen-free atmosphere was maintained by a metallic zirconium trap located in the hot zone of the calorimeter.

\subsubsection{Scanning electron microscopy (SEM)}

Morphology and overall composition of the AuNi samples after HTXRD heat treatment and DSC measurement were observed by scanning electron microscopy (SEM) using a TESCAN LYRA 3XMU FEG/SEM microscope with an X-Max 80 EDX Oxford Instruments detector.

\section{Results and discussion}

The samples of the AuNi nanoparticles in hexane were characterized by various methods. The hydrodynamic size of the AuNi NPs was measured by the dynamic light scattering (DLS) method (see Table 2). Size and shape of the individual AuNi NPs were investigated by transmission electron microscopy (TEM). An example of the AuNi nanoparticles is in Fig. 3 where an average size and shape of the metal cores of the AuNi nanoparticles can be recognized.

The average size of the metal core was evaluated by image analysis of the TEM photos. The average nanoparticle core size (diameter) of the spherical AuNi nanoparticles in Fig. 3 (left) is $15 \mathrm{~nm}$. The uniform nanoparticles have revealed a tendency to self-assembling (see monolayer and double layer parts in Fig. 3 (right)). Sometimes the ideal spheres are disturbed by twin crystal boundaries.

The metallic composition of the AuNi NP samples was obtained by inductively-coupled plasma atomic emission spectroscopy (ICP-OES). The metallic fraction inside AuNi NPs was controlled (results are in Table 2) by the gold/nickel precursor molar ratios used for the synthesis.

The synthesized AuNi NP colloids in hexane were brown. The UV/ Vis spectroscopy of the samples revealed the plasmon resonance in the visible region with maxima $\lambda \approx 520 \mathrm{~nm}$, which is in good relation to work of Leff on Au NPs $\left(\lambda_{\mathrm{Au}} \approx(500-550) \mathrm{nm}\right)$ [43] and to work of Bethany on 1-dodecanthion capped AuNi NPs $\left(\lambda_{\mathrm{AuNi}} \approx 525 \mathrm{~nm}\right)$ in toluene [13].

Table 2 shows also the ratio between the hydrodynamic and metal core sizes of the nanoparticles. The difference of the size is given by existence of the stabilizing organic layer, which can have a high mass fraction (see a mass fraction of organic matter in Table 2). This fraction can be partly lowered if the purifying procedure is repeated several times (see sample AuNi 2) but this procedure results in decreasing yields of the AuNi NPs. The organic layer was observed using IR spectroscopy (Fig. 4). The IR spectra of the oleylamine capped particles show a difference in the region about $3800 \mathrm{~cm}^{-1}$ if compared to those for neat oleylamine.

The transmission electron microscopy of the AuNi nanoparticles was performed. The nanoparticles were exposed to the energy of the electron beam in a vacuum. The beam energy increases the sample a

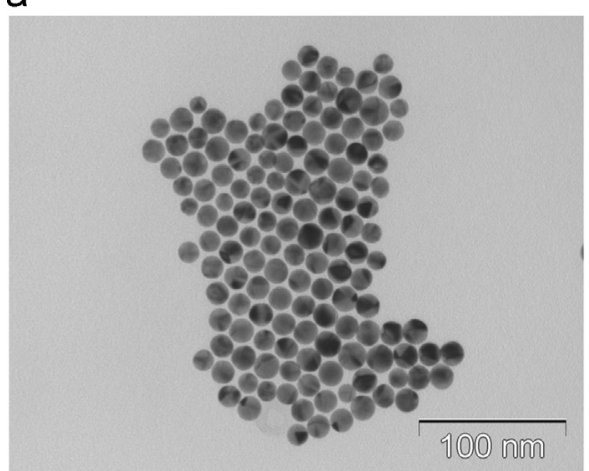

b

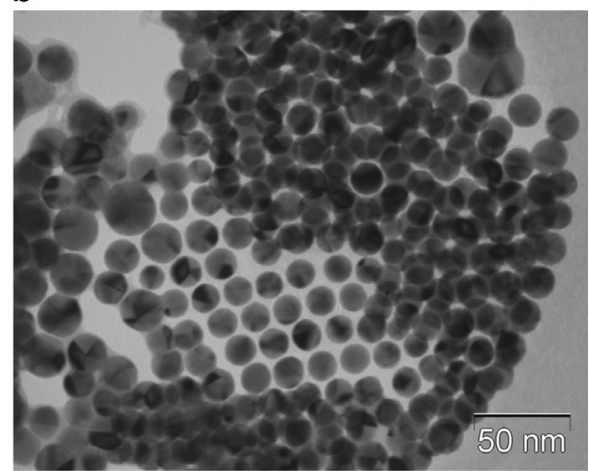

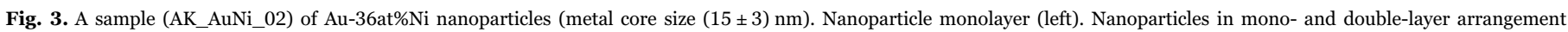
(right). TEM micrographs. 


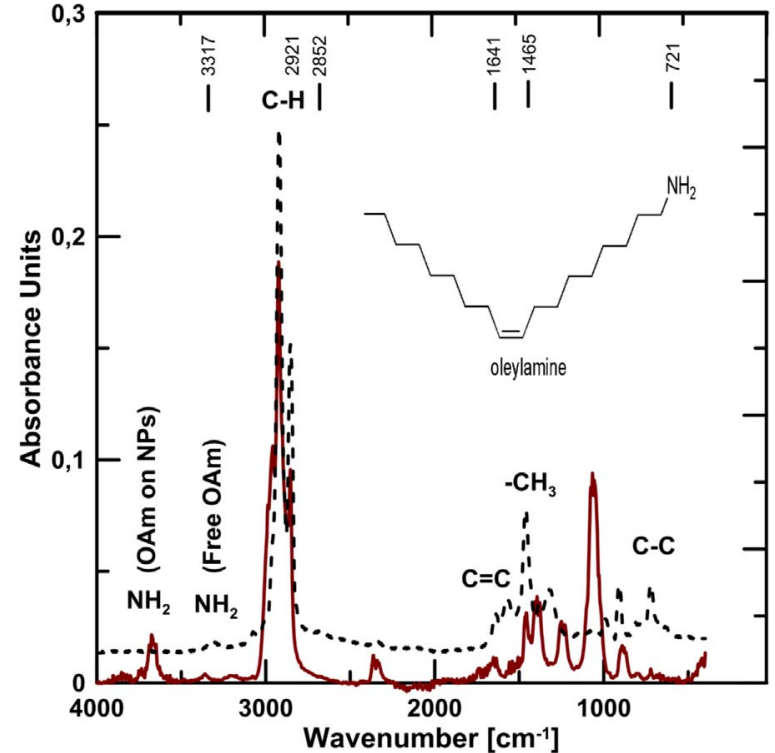

Fig. 4. The IR spectra of the oleylamine - capped particles (red line). Neat oleylamine (black line and wavenumbers). The great difference $\left(-\mathrm{NH}_{2}\right)$ is at about $3800 \mathrm{~cm}^{-1}$. (For interpretation of the references to color in this figure legend, the reader is referred to the web version of this article.)

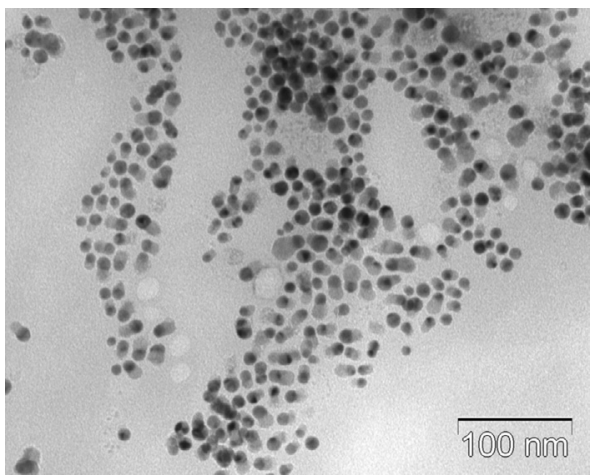

Fig. 5. The TEM micrograph of the sample (AuNi 1) of dumbbell nanoparticles formed by spinodal decomposition transformation inside an electron microscope. The Au-rich FCC phase gives dark dumbbell ends, the Ni-rich FCC phase gives light dumbbell ends (left).

temperature in general. The absolute temperature of the sample was not known but the effect of the spinodal decomposition was observed. The image of the AuNi nanoparticles after the spinodal decomposition is shown in Fig. 5. The nanoparticles have a dumbbell nature, where one part is rich in gold and the second part is rich in nickel.

The spinodal decomposition of the AuNi NPs is similar to AuNi alloy spinodal decomposition observed at low-temperature region [2]. This kind of decomposition was observed also for other bimetallic nanoparticles. More detailed experimental and theoretical investigation can be found in work of Dahan and co-workers on BiSn nanoparticles [45]. In the case of AuNi spinodal decomposition, neither the value of the temperature nor chemical compositions of the coexisting phases were available from applied electron microscopy instrumentation.

The indication of the decomposition of the FCC phase was also inferred from high-resolution transmission electron microscopy (HRTEM). The atomic resolution image of selected AuNi nanoparticle is given in Fig. 6. The crystal lattice of the selected nanoparticle is visualized and the regions of different chemical compositions can be visualized. These regions are separated by phase boundaries of a different kind (a diffusion boundary and a twin crystal boundary). The electron diffraction of the phase regions showed the FCC patterns

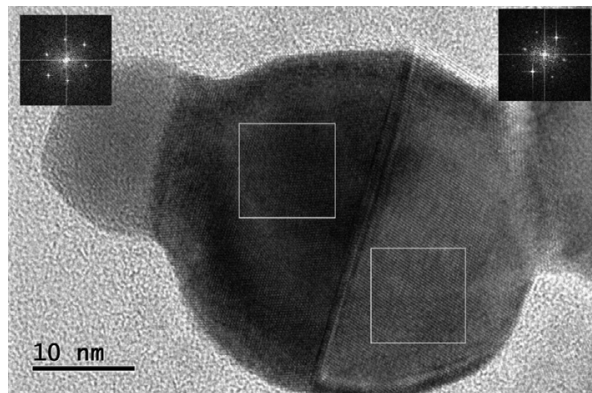

Fig. 6. Atomic resolution image of selected AuNi nanoparticle (sample AuNi 1). Electron diffractograms in insets indicate the FCC lattice of Au-rich and Ni-rich phase regions. The phase regions are separated by a twinned crystal boundary (center) and a diffusion phase boundary (left).

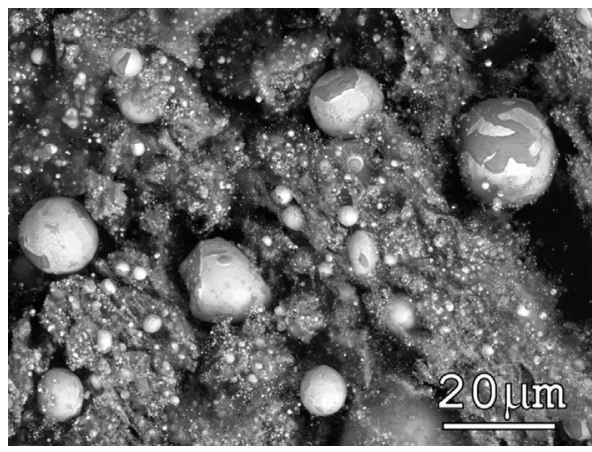

Fig. 7. The AuNi NPs after heating to $1200^{\circ} \mathrm{C}$ under argon (sample AuNi 4). The spherical microparticles are separated by carbon-containing matter. The light grey regions of the spherical microparticles are rich in gold (FCC_Au phase). The dark grey regions are rich in nickel (FCC_Ni phase). SEM micrograph, a signal of back scattered electrons (BSE).

with lattice parameters near the gold and nickel FCC lattice parameters within the limits of the accuracies. The central nanoparticle in Fig. 6 is joined with two satellite nanoparticles (joined from the left and right side). It reveals Ostwald ripening. The satellite and central particle are facing one to other with the FCC phase rich in the same metal.

The AuNi NPs were also heat treated under argon at $1200{ }^{\circ} \mathrm{C}$ inside a DSC apparatus ( 3 cycles of heating and cooling at $10 \mathrm{~K} / \mathrm{min}$ ). The DSC signal revealed only an exothermic effect at approx. $300{ }^{\circ} \mathrm{C}$ and no exo/endothermic effects during the first heating at higher temperature range to $1200{ }^{\circ} \mathrm{C}$. The absence of an exo/endo peaks confirm theoretical conclusions. The well reproduced endothermic effect was observed at $935{ }^{\circ} \mathrm{C}$ during heating in the $2 \mathrm{nd}$ and $3 \mathrm{rd}$ heating cycles. The origin of the endothermic effect may concern nickel oxide formed by the reaction of metal with trace oxygen impurities in Ar gas during measurement.

The resulting microstructure of the sample Au-63 at\%Ni (AuNi 1) after DSC experiments is in Fig. 7. The formation of the spherical microparticles indicates that the sample was heated above solidus temperature (i.e. in the (liquid+FCC) phase region). The rate of the cooling enables massive spinodal transformation to FCC_Au and FCC_Ni phases. The metal composition of the Au rich phase was Au$(49 \pm 10)$ at $\% \mathrm{Ni}$ after cooling (EDAX measurement). The composition of the Ni-rich phase was $\mathrm{Au}-(92 \pm 2)$ at\%Ni. The EDX chemical analysis is in agreement with both nickel and gold mapping of the selected spherical microparticles Fig. 8. The matter in between spherical microparticles in Fig. 7 involves a high portion of carbon as results of pyrolysis of the oleylamine that originally stabilized the AuNi NPs.

The XRD powder diffraction was used for sample characterization. The suspension of the AuNi NPs in hexane was placed on the holder and the solvent was evaporated. The diffractions of the samples were measured and the example is displayed in Fig. 9. This method enables to evaluate phase composition. The XRD diffraction pattern reveals the 

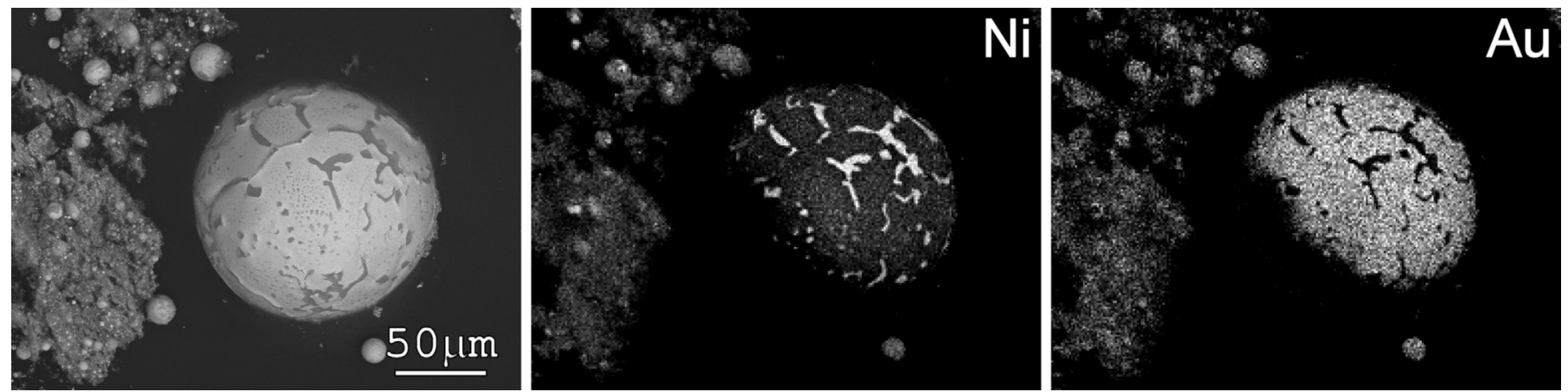

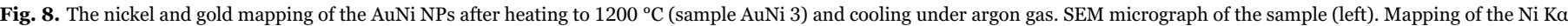
(center) and the Au La signal (right).

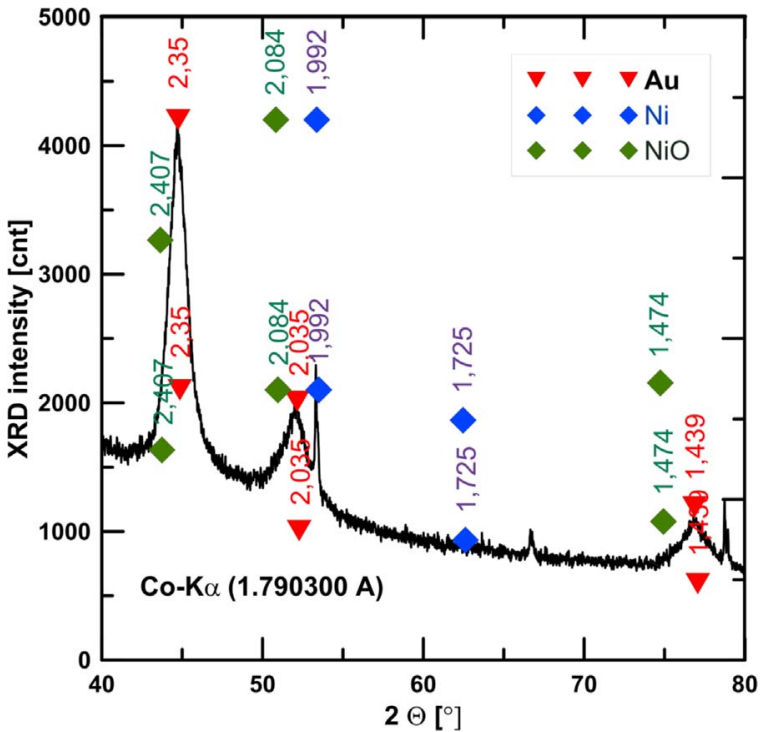

Fig. 9. Powder X-ray diffractions (XRD) of the AuNi nanoparticle sample (AuNi 4) decomposed spinodally to FCC_Au FCC_Ni phases.

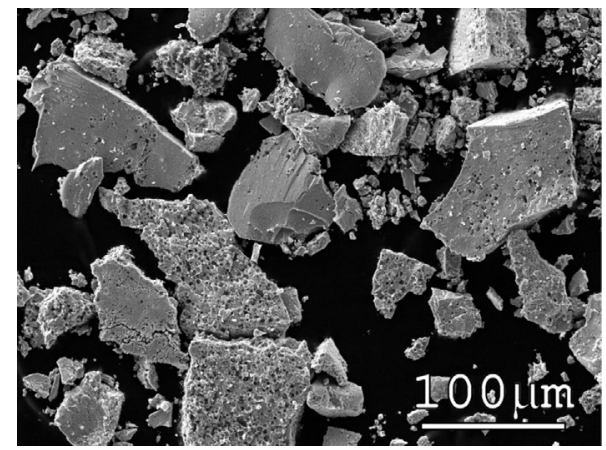

Fig. 10. The structure involving the individual particles of the AuNi nanoalloy (sample AuNi 3 after heating to $400{ }^{\circ} \mathrm{C}$ and cooling. SEM micrographs, a signal of secondary electrons.

peaks of FCC gold and FCC nickel. The large width of the diffraction peaks indicates the nano-crystallinity of the sample. The presence of both gold and nickel metals diffractions indicates spinodal decomposition of the AuNi NPs. The widths of the samples changed to thin if the samples were heat treated above $430{ }^{\circ} \mathrm{C}$. The sintering effect of the FCC_Au and FCC_Ni phases occurred (Fig. 9, right). The formation of the nickel oxide (onset at $430{ }^{\circ} \mathrm{C}$ up to $6 \mathrm{wt} \%$ at $500^{\circ} \mathrm{C}$ ) was indicated using HTXRD if the samples were heated to $500^{\circ} \mathrm{C}$ by rate $5 \mathrm{~K} / \mathrm{min}$ under air.

The microstructure of the samples after heating to $400{ }^{\circ} \mathrm{C}$ is in
Fig. 10. The more detailed SEM micrograph shows an average individual particle size ranging between $20-40 \mathrm{~nm}$. The formation of the microparticles was not observed after heat treatment to $400{ }^{\circ} \mathrm{C}$ (compare microparticles heated to $1200{ }^{\circ} \mathrm{C}$ in Fig. 7).

The AuNi nanoparticles were characterized by experimental methods as detailed in this chapter. A better understanding of the observed effects was obtained. The results of the heat treatment of the samples under inert gas and under air enabled to propose a scheme given in Fig. 11. The AuNi NPs undergo easily the spinodal decomposition (compare Fig. 5) at elevated temperatures. The heating above the melting temperature under inert gas results in AuNi bulk alloy that features two-phase structure (Fig. 7 and Fig. 8). The AgNi nanoparticles studied by our colleague $[46,47]$ reveal similar spinodal decomposition effects. The studies of both AuNi and AgNi nanoparticles under different heat and gas conditions are important for subsequent investigations focused on catalytic oxidation of organic substances on the surface of nickel-based metal nanoparticles that were studied also by our team [48].

\section{Conclusions}

The theoretical prediction of the Au-Ni nanoalloy phase diagram was calculated by the extended CALPHAD method. The details of the calculations are given. The depressions of both liquidus and solidus were predicted as well as the phase transformation depression of the (FCC_Ni rich + FCC_Au rich) /(FCC solid solution) phase boundary (see Fig. 2). The spinodal decomposition of the AuNi solid solution was predicted in the (FCC_Ni rich + FCC_Au rich) phase region.

The AuNi nanoparticles were synthesized by the solvothermal method and the thermal stability under argon and air was investigated. The samples after heat treatment were characterized in situ or ex-post by various techniques.

The experimental observations of the AuNi nanoparticles confirm that the particles are stabilized in colloid solution by oleylamine ligands. The dry samples of the AuNi nanoalloy reveal spinodal decomposition to FCC gold rich and FCC nickel-rich phases at elevated temperatures. The DSC method confirmed that oleylamine ligand layer degrades at approx. $300^{\circ} \mathrm{C}$ under argon. The absence of the thermal effect in the case when the nanoparticles form FCC solid solution phase from spinodally decomposed sample at the high-temperature range was confirmed experimentally. The spherical AuNi microparticles were observed in inert gas experiments after cooling to ambient temperature although there was no heating above the bulk solidus temperature.

The AuNi dry samples spinodally transform. Above $450{ }^{\circ} \mathrm{C}$, the samples form bulk composites that consist of a gold-rich matrix and nickel-rich micro-sized particles.

The experimental investigation confirmed that AuNi nanoparticles are sensitive to an increase of temperature. The special care has to be taken to remove oxygen even in traces. Aggregation may occur if the stabilizing oleylamine ligand layer is disturbed. 


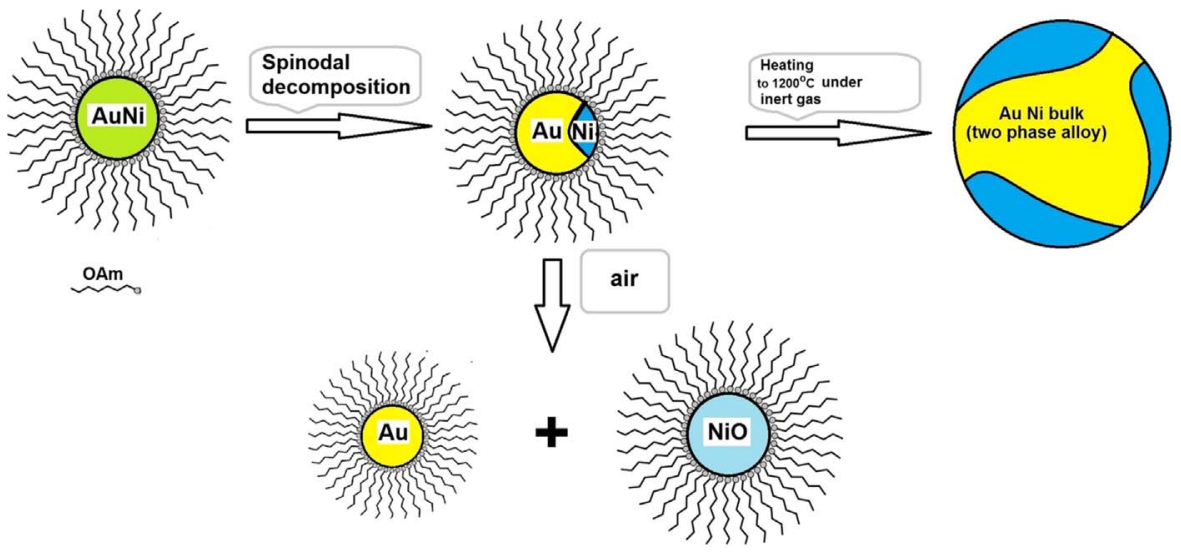

Fig. 11. The scheme of the AuNi nanoparticle chemical and phase conversions.

\section{Acknowledgements}

Financial support of the Czech Science Foundation for the project "Stability and phase equilibria of bimetallic nanoparticles, GA14$12653 \mathrm{~S}$ ” is gratefully acknowledged. The acknowledgment to the projects GA17-15405S and GA17-12844S are also given. The results of this research have been acquired within CEITEC 2020 (LQ1601) project with the financial contribution made by the Ministry of Education, Youths and Sports of the Czech Republic within special support paid from the National Programme for Sustainability II funds.

\section{Appendix A. Supplementary material}

Supplementary data associated with this article can be found in the online version at doi:10.1016/j.calphad.2017.05.002.

\section{References}

[1] J. Wang, X.-G. Lu, B. Sundman, X. Su, Thermodynamic assessment of the Au-Ni system, Calphad 29 (2005) 263-268. http://dx.doi.org/10.1016/j.calphad.2005.09.004.

[2] J.-C. Zhao, M.R. Notis, Ordering transformation and spinodal decomposition in Au-Ni alloys, Metall. Mater. Trans. A 30/3 (1999) 707-716 (WOS: 000078868700022).

[3] J. Wang, L.B. Liu, H.S. Liu, Z.P. Jin, Assessment of the diffusional mobilities in the face-centred cubic Au-Ni alloys, Calphad 31 (2007) 249-255. http://dx.doi.org/ 10.1016/j.calphad.2006.11.006.

[4] Y. Asai, Y. Isobe, K. Nakai, C. Kinoshita, K. Shinohara, Inducement process and mechanism of spinodal decomposition in electron-irradiated Au-Ni alloys, J. Nucl. Mater. 179-181 (1991) 1050-1052. http://dx.doi.org/10.1016/0022-3115(91) 90272-9.

[5] D. Wang, P. Schaaf, Ni-Au bi-metallic nanoparticles formed via dewetting, Mater. Lett. 70 (2012) 30-33. http://dx.doi.org/10.1016/j.matlet.2011.11.102.

[6] A. Herz, D. Wang, R. Müller, P. Schaaf, Formation of supersaturated Au-Ni nanoparticles via dewetting of an Au/Ni bilayer, Mater. Lett. 102-103 (2013) 22-25. http://dx.doi.org/10.1016/j.matlet.2013.03.096.

[7] A. Herz, D. Wang, P. Schaaf, Dewetting of Au/Ni bilayer films on prepatterned substrates and the formation of arrays of supersaturated Au-Ni nanoparticles, J. Vac. Sci. Technol. B: Microelectron. Nanometer Struct. 32 (2014) 21802. http:// dx.doi.org/10.1116/1.4863320.

[8] C.-C. Kuo, C.-Y. Li, C.-H. Lee, H.-C. Li, W.-H. Li, Huge inverse magnetization generated by Faraday induction in nano-sized Au@Ni core@shell nanoparticles, Int. J. Mol. Sci. 16 (2015) 20139-20151. http://dx.doi.org/10.3390/ ijms160920139.

[9] H.-K. Chiu, I.-C. Chiang, D.-H. Chen, Synthesis of NiAu alloy and core-shell nanoparticles in water-in-oil microemulsions, J. Nanopart. Res. 11 (2009) 1137-1144. http://dx.doi.org/10.1007/s11051-008-9506-9.

[10] N.R. Nik Roselina, A. Azizan, K.M. Hyie, M.C. Murad, A.H. Abdullah, Synthesis and characterization of $\mathrm{Ni}-\mathrm{Au}$ bimetallic nanoparticles, Int. J. Mod. Phys. B 29 (2015) 1540006. http://dx.doi.org/10.1142/S0217979215400068.

[11] P. He, X. Wang, Y. Liu, L. Yi, X. Liu, Reverse micelle synthesis of AuNi alloy as electrocatalyst of borohydride oxidation, Int. J. Hydrog. Energy 37 (2012) 1254-1262. http://dx.doi.org/10.1016/j.ijhydene.2011.09.144.

[12] S. Petrović, D. Milovanović, B. Salatić, D. Peruško, J. Kovač, G. Dražić, M. Mitrić, M. Trtica, B. Jelenković, Composition and structure of NiAu nanoparticles formed by laser ablation of Ni target in Au colloidal solution, Mater. Chem. Phys. 166 (2015) 223-232. http://dx.doi.org/10.1016/j.matchemphys.2015.10.007.

[13] B.J. Auten, B.P. Hahn, G. Vijayaraghavan, K.J. Stevenson, B.D. Chandler,
Preparation and characterization of $3 \mathrm{~nm}$ magnetic NiAu nanoparticles, J. Phys. Chem. C 112 (2008) 5365-5372. http://dx.doi.org/10.1021/jp076982c.

[14] L. Jia, X. Pei, F. Zhou, W. Liu, Unconventional assembly of bimetallic Au-Ni janus nanoparticles on chemically modified silica spheres, Chem. - A Eur. J. 20 (2014) 2065-2070. http://dx.doi.org/10.1002/chem.201303659.

[15] K. Suzuki, T. Yamaguchi, K. Matsushita, C. Iitsuka, J. Miura, T. Akaogi, H. Ishida, Aerobic oxidative esterification of aldehydes with alcohols by gold-nickel oxide nanoparticle catalysts with a core-shell structure, ACS Catal. 3 (2013), 2013, pp. 1845-1849. http://dx.doi.org/10.1021/cs4004084.

[16] X. Wang, S. Sun, Z. Huang, H. Zhang, S. Zhang, Preparation and catalytic activity of PVP-protected $\mathrm{Au} / \mathrm{Ni}$ bimetallic nanoparticles for hydrogen generation from hydrolysis of basic NaBH4 solution, Int. J. Hydrog. Energy 39 (2014) 905-916. http://dx.doi.org/10.1016/j.ijhydene.2013.10.122.

[17] A. Sánchez-Iglesias, M. Grzelczak, B. Rodríguez-González, P. Guardia-Girós, I. Pastoriza-Santos, J. Pérez-Juste, M. Prato, L.M. Liz-Marzán, Synthesis of multifunctional composite microgels via In Situ Ni growth on pNIPAM-coated $\mathrm{Au}$ nanoparticles, ACS Nano 3 (2009) 3184-3190. http://dx.doi.org/10.1021/ nn9006169.

[18] A. Herz, M. Friák, D. Rossberg, M. Hentschel, F. Theska, D. Wang, D. Holec, M. Šb, O. Schneeweiss, P. Schaaf, Facet-controlled phase separation in supersaturated Au-Ni nanoparticles upon shape equilibration, Appl. Phys. Lett. 107 (2015) 73109. http://dx.doi.org/10.1063/1.4928627.

[19] J. Lee, K.J. Sim, General equations of CALPHAD-type thermodynamic description for metallic nanoparticle systems, Calphad 44 (2014) 129-132. http://dx.doi.org/ 10.1016/j.calphad.2013.07.008.

[21] K. Sim, J. Lee, Phase stability of Ag-Sn alloy nanoparticles, J. Alloy. Compd. 590 (2014) 140-146. http://dx.doi.org/10.1016/j.jallcom.2013.12.101.

[20] J. Park, J. Lee, Phase diagram reassessment of Ag-Au system including size effect, Calphad 32 (2008) 135-141. http://dx.doi.org/10.1016/j.calphad.2007.07.004.

[22] J. Sopousek, J. Vrestal, J. Pinkas, P. Broz, J. Bursik, A. Styskalik, D. Skoda, O. Zobac, J. Lee, $\mathrm{Cu}-\mathrm{Ni}$ nanoalloy phase diagram - Prediction and experiment, Calphad 45 (2014) 33-39. http://dx.doi.org/10.1016/j.calphad.2013.11.004.

[23] J. Lee, T. Tanaka, J. Lee, H. Mori, Effect of substrates on the melting temperature of gold nanoparticles, Calphad 31 (2007) 105-111. http://dx.doi.org/10.1016/ j.calphad.2006.10.001.

[24] J.A.V. Butler, The thermodynamics of the surfaces of solutions, Proc. R. Soc. A 135 (1932) 348-375.

[25] T. Tanaka, K. Hack, T. Iida, S. Hara, Application of thermodynamic databases to the evaluation of surface tensions of molten alloys, salt mixtures and oxide mixtures, Z. Met. 87 (1996) 380-389 (WOS:A1996UM18700008).

[26] R. Picha, J. Vřeštál, A. Kroupa, Prediction of alloy surface tension using a thermodynamic database, Calphad 28 (2004) 141-146. http://dx.doi.org/10.1016/ j.calphad.2004.06.002.

[27] J. Lee, M. Nakamoto, T. Tanaka, Thermodynamic study on the melting of nanometer-sized gold particles on graphite substrate, J. Mater. Sci. 40 (2005) 2167-2171. http://dx.doi.org/10.1007/s10853-005-1927-6.

[28] L.E. Murr, Interfacial Phenomena in Metals and Alloys, Addison-Wesley Publishing Company, London, 1975, p. 124.

[29] T. Iida, R.I.L. Guthrie, The Physical Properties of Liquid Metals, Oxford Science Publications, 1993, p. $8(9,14,71)$.

[30] G. Lohofer, J. Brillo, I. Egry, Thermophysical properties of undercooled liquid $\mathrm{Cu}$ ? Ni alloys, Int. J. Thermophys. 25 (2004) 1535-1550. http://dx.doi.org/10.1007/ s10765-004-5757-6.

[31] A. Shirinyan, M. Wautelet, Y. Belogorodsky, Solubility diagram of the $\mathrm{Cu}-\mathrm{Ni}$ nanosystem, J. Phys.: Condens. Matter 18 (2006) 2537-2551. http://dx.doi.org/ 10.1088/0953-8984/18/8/016.

[32] R. Brooks, I. Egry, S. Seetharaman, D. Grant, Reliable data for high-temperature viscosity and surface tension: results from a European project, High. Temp.-High Press. 33 (2001) 631-637. http://dx.doi.org/10.1068/htwu323.

[33] F. Xiao, R. Yang, C. Zhang, Surface tension of molten Ni-W and Ni-Cr alloys, Mater. Sci. Eng.: B. 132 (2006) 183-186. http://dx.doi.org/10.1016/ j.mseb.2006.02.017.

[34] F. Xiao, L. Liu, R. Yang, H. Zhao, L. Fang, C. Zhang, Surface tension of molten Ni(Cr, Co, W) alloys and segregation of elements, Trans. Nonferr. Met. Soc. China 18 
(2008) 1184-1188. http://dx.doi.org/10.1016/S1003-6326(08)60202-2.

[35] H.Y. Hou, G.L. Chen, G. Chen, Y.L. Shao, A molecular dynamics simulation on surface tension of liquid $\mathrm{Ni}$ and $\mathrm{Cu}$, Comput. Mater. Sci. 46 (2009) 516-519. http://dx.doi.org/10.1016/j.commatsci.2009.04.001.

[36] S.D. Korkmaz, ş. Korkmaz, Investigation of surface properties of liquid transition metals: surface tension and surface entropy, Appl. Surf. Sci. 257 (2010) 261-265. http://dx.doi.org/10.1016/j.apsusc.2010.06.082.

[37] J. Brillo, I. Egry, Surface tension of nickel, copper, iron and their binary alloys, J. Mater. Sci. 40 (2005) 2213-2216. http://dx.doi.org/10.1007/s10853-005-1935-6.

[38] W.H. Qi, M.P. Wang, Q.H. Liu, Shape factor of nonspherical nanoparticles, J. Mater. Sci. 40 (2005) 2737-2739. http://dx.doi.org/10.1007/s10853-005-2119-0.

[39] J.-G. Lee, H. Mori, H. Yasuda, In situ high-resolution electron microscope observation of phase change in nanometer-sized alloy particles, J. Mater. Res. 20 (2005) 1708-1721. http://dx.doi.org/10.1557/JMR.2005.0223.

[40] G. Guisbiers, M. Wautelet, Size, shape and stress effects on the melting temperature of nano-polyhedral grains on a substrate, Nanotechnology 17 (2006) 2008-2011. http://dx.doi.org/10.1088/0957-4484/17/8/036.

[41] A. Zhang, Z. Zhu, Y. He, G. Ouyang, Structure stabilities and transitions in polyhedral metal nanocrystals: an atomic-bond-relaxation approach, Appl. Phys. Lett. 100 (2012) 171912. http://dx.doi.org/10.1063/1.4706260.
[42] E. Ringe, R.P. Van Duyne, L.D. Marks, Wulff construction for alloy nanoparticles, Nano Lett. 11 (2011) 3399-3403. http://dx.doi.org/10.1021/nl2018146.

[43] D.V. Leff, L. Brandt, J.R. Heath, Synthesis and characterization of hydrophobic organically-soluble gold nanocrystals functionalized with primary amines, Langmuir 12 (1996) 4723-4730. http://dx.doi.org/10.1021/la960445u.

[44] J. Sopoušek, J. Pinkas, P. Brož, J. Buršík, V. Vykoukal, D. Škoda, A. Stýskalík, O. Zobač, J. Vřeštál, A. Hrdlička, J. Simbera, Ag-Cu colloid synthesis: bimetallic nanoparticle characterisation and thermal treatment, J. Nanomater. 2014 (2014) 1-13. http://dx.doi.org/10.1155/2014/638964.

[45] Y. Dahan, G. Makov, R.Z. Shneck, Nanometric size dependent phase diagram of BiSn, Calphad 53 (2016) 136-145. http://dx.doi.org/10.1016/j.calphad.2016.04.006.

[46] Vit, Vykoukal, Jiri Bursik, Pavla Roupcova, Jiri, Pinkas, 'Solvothermal hot injection synthesis of AgNi nanoalloy', conference proceedings Nanotech France, 2016.

[47] Vit Vykoukal, Jiri Bursik, Pavla Roupcova, Jiri Pinkas, 'Solvothermal Hot Injection Synthesis of AgNi Nanoalloy', manuscript in preparation.

[48] P. Brož, M. Hejduková, V. Vykoukal, F. Zelenka, J. Sopoušek, J. Burš́́k, O. Zobač Study of surface effects and catalytic properties of selected Ni-based bimetallic nanoparticles by Knudsen effusion mass spectrometry, Calphad, prepared for publication. 